\title{
Title: Natural IgA and TNFRSF13B polymorphism: a double edged sword fueling balancing selection
}

Authors: Jeffrey L. Platt ${ }^{1 *}$, Mayara Garcia de Mattos Barbosa ${ }^{2}$, Daniel Huynh ${ }^{2}$, Adam R. Lefferts ${ }^{2}$, Juhi Katta $^{2}$, Cyra Kharas ${ }^{2}$, Peter Freddolino ${ }^{3}$, Christine M. Bassis ${ }^{4}$, Christiane Wobus ${ }^{5}$, Raif Geha ${ }^{6}$, Richard Bram $^{7}$, Gabriel Nunez ${ }^{8}$, Nobuhiko Kamada ${ }^{4}$ and Marilia Cascalho ${ }^{1 *}$

\section{Affiliations:}

${ }^{1}$ Department of Microbiology and Immunology and Department of Surgery, University of

Michigan, Ann Arbor, Michigan, 48109, USA

${ }^{2}$ Department of Surgery, University of Michigan, Ann Arbor, Michigan, 48109, USA

${ }^{3}$ Department of Biological Chemistry and Department of Computational Medicine and

Bioinformatics, University of Michigan, Ann Arbor, Michigan, 48109, USA

${ }^{4}$ Department of Medicine, University of Michigan, Ann Arbor, Michigan, 48109, USA

$15{ }^{5}$ Department of Microbiology and Immunology, University of Michigan, Ann Arbor, Michigan, 48109, USA

${ }^{6}$ Department of Pediatrics, Boston Children's Hospital, Boston, Massachusetts, 02115 USA

${ }^{7}$ Departments of Oncology, Pediatric Hematology/Oncology and Pediatrics, Mayo Clinic, Rochester, Minnesota, 55905, USA

${ }^{8}$ Department of Pathology, University of Michigan, Ann Arbor, Michigan, 48109, USA

*Correspondence to: marilia@umich.edu (MC) or plattj1@umich.edu (JLP).

Conflict of Interest Statement: "The authors have declared that no conflict of interest exists."

Main Manuscript Length:

Words: 4,051

Characters w/o spaces: 23,047

Characters with spaces: 27,229 
One Sentence Summary: TACI-variants block entero-bacteria spread

Abstract: TNFRSF13B encodes the "transmembrane-activator and CAML-interactor" (TACI) receptor, which drives plasma cell differentiation. Although TNFRSF13B supports host defense, dominant-negative TNFRSF 13B alleles are common in humans and other species and only rarely associate with disease. We reasoned the high frequency of disruptive $T N F R S F 13 B$ alleles reflects balancing selection, the loss of function conferring advantage in some settings. Testing that concept, we asked whether and how a common human dominant negative variant, TNFRSF13B A181E, imparts resistance to enteric pathogens. Mice engineered to express mono-allelic or bi-allelic A144E variants of tnrsf13B, corresponding to A181E exhibited striking resistance to pathogenicity and transmission of $C$. rodentium, a murine pathogen that models enterohemorrhagic E. coli, and resistance was principally owed to deficiency of natural IgA in the intestine. In wild type mice with gut IgA and in mutant mice fed IgA, binding of Ig induces expression of LEE encoded virulence genes, which confer pathogenicity and transmission. C. rodentium and probably

15 some other enteric organisms thus appropriated binding of otherwise protective antibodies to signal induction of the virulence program and the high prevalence of TNFRSF13B dominant negative variants thus reflects balancing selection. 


\section{Main Text:}

\section{Introduction:}

TNFRSF $13 B$ encodes the "transmembrane activator and CAML interactor" (TACI), a member of the TNF receptor superfamily and has been considered vital to immune fitness. TACI is the receptor for the B cell activating factor (BAFF) and "a proliferation induced ligand" (APRIL). Binding of BAFF or APRIL to TACI activates BLIMP-1 (1), the transcription factor that governs differentiation of B lymphocytes into plasma cells (2-4). Common variable immunodeficiency and IgA deficiency in humans and mice has been associated with TNFRSF13B null and dominant negative mutations $(5,6)$.

Since TNFRSF13B in humans supports a key facet of immune fitness, it might be surprising that surveys of normal populations reveal extraordinary polymorphism - 951 TNFRSF13B missense and only 383 synonymous mutations (https://useast.ensembl.org/index.html) - and a high frequency of dominant negative alleles (7). Indeed, most individuals with TNFRSF13B variants that disrupt function are healthy $(7,8)$. Nor is this paradoxical diversity limited to humans, as TNFRSF13B polymorphism also occurs in other species. For example, 17 missense, 2 stop gained and 2 splice variants have been reported in mice (https://useast.ensembl.org/index.html) (9). The mechanism underlying TNFRSF13B polymorphism is unknown, although missense alleles appear to have been selectively retained in populations and the McDonald-Kreitman neutrality index indicates the locus is under strong positive selection. This is in contrast to genes encoding HLA which are under moderate purifying pressure (10).

The diversification of TNFRSF $13 B$ across species, the high frequency of dominant negative variants and the evidence of positive selection suggested to us that the biological impact of TNFRSF13B functions are incompletely understood. To explore potential functions of TNFRSF13B and pressures for diversification, we tested the impact of allele variants embodying the range of functions of TNFRSF13B on resistance to 
and transmission of Citrobacter rodentium (C. rodentium), in mice which models enterohemorrhagic Escherichia coli (E. coli) in humans (11). We wondered whether the high frequency of TNFRSF13B polymorphisms and the frequent dominant negative phenotypes across species could reflect an adaptation to resist common enteric pathogens.

\section{Results:}

\section{Tnfrsf $13 b$ controls resistance to $C$. rodentium}

We first asked whether or to which extent tnfrsf $13 b$ mutations modify susceptibility of naïve mice to infection with C. rodentium. Accordingly, the smallest number of C. rodentium $\left(10^{8}\right)$ that reliably generates disease were given to wild type (C57BL/6 mice and to mice of the same background (i) with mono-allelic or bi-allelic tnfrsf13b mutations encoding mA144E (homologous to the frequent human A181E mutation) and to mice (ii) with fully disrupted thfrsf $13 b$ and monitored excretion of viable organisms in stool during the ensuing month. Because gut microbiota potentially influence the virulence of $C$. rodentium (12), mutant and wild type mice used in these experiments were co-housed for 4 weeks prior to infection to allow admixture of flora.

After introduction of C. rodentium, wild type mice typically develop a mild diarrheal disease commencing at 5-7 days, reaching greatest severity at 7-10 days, and resolving at 18-28 days; infection typically elicits immunity that imparts enduring resistance to subsequent infection (11). Consistent with that experience, wild type mice exhibited maximum excretion of $10^{7}-10^{9}$ viable $C$. rodentium between 7 days and 21 days post-infection and resolution by 35 days. In notable contrast, mice with mono-allelic mutations encoding A144E variants excreted on average 10 -fold less viable $C$. rodentium than wild type mice $(\mathrm{p}=0.0246)$ and all mice with bi-allelic mutations and all but one with full disruption of tnfrsfl $3 b$ excreted no viable organisms $(\mathrm{p}<0.0001)$ (Figure 1A). Perhaps more important, the total number of viable C. rodentium excreted during the course of the experiments by mutant mice was profoundly lower than the total number excreted by wild type mice ( $\mathrm{p}=0.0002$ ) (Figure 1B). Thus, mutations of $\operatorname{tnf}$ frsf $13 b$ that disrupt the function 
of the encoded protein decrease susceptibility to $C$. rodentium infection and this decrease is appreciated days before adaptive immunity might begin to be manifest.

Since TNFRSF13B mutations confer baseline resistance to C. rodentium, we wondered resistance could be mediated by natural antibodies, which are known to confer resistance to other bacteria (13). Although TNFRSF 13B mutations decrease overall production of natural antibodies (14), it is possible that natural antibodies specific for $C$. rodentium might nonetheless be present and underlie resistance in mutant mice. Indeed, Tnfrsf13b mutant mice had less natural IgM but no less natural IgG in the blood (Figure S1A). However, analysis of serum revealed mutant mice had no appreciable natural IgM or natural IgG in blood that could bind C. rodentium (Figure S1B). More important, analysis of stool from un-manipulated mutant and wild type mice revealed that wild type but not mutant mice had natural enteric IgA that bound $C$. rodentium (Figure 1C). Thus, the baseline resistance of mutant mice to C. rodentium infection is not mediated by natural antibodies. responses do so. To detect an early primary Ig response, we assayed the blood and stool of the various strains for presence of $C$. rodentium specific Ig 7 days after infection with that organism (Figure S2). Six of eight wild type and only 2 of 30 tnfrsf $13 b$ mutant mice had IgM specific for $C$. rodentium in blood seven days after infection (Figure S2A). Both wild type and tnfrsfl3b mutant mice had C. rodentium-specific IgG, but the concentrations were low $(<10 \mu \mathrm{g} / \mathrm{ml})$ (Figure S2B). Twenty one days after infection, when adaptive IgG responses are generally detected, all wild type but fewer than one half of mutant mice had $C$. rodentium specific IgG. Since antibodies that protect against $C$. rodentium target intimin (a virulence factor) we measured the concentration of these antibodies in the serum of mice before and after infection. Intimin-specific antibodies were not observed in any strain until 14-21 days after infection and levels in 25 wild type mice exceeded levels in mutant mice $(\mathrm{p}<0.01)$, (Figure S2D). Wild type mice also produced significantly more intimin-specific IgA than tnfrsf $13 b$-mutant mice 21 days after infection (Figure S2E). 
Thus, hastened primary antibody responses do not explain heightened resistance of thfrsfl $13 \mathrm{~b}$ mutant mice to $C$. rodentium.

\section{The tnfrsfl3b genotype determines development of virulence by $C$. rodentium.}

Since productive infection with C. rodentium requires acquisition of virulence in the host environment (12), we wondered whether mutations of tnfrsf $13 b$ could block such acquisition. To answer that question we assayed development of virulence by $C$. rodentium engineered to express a ler bioluminescent reporter gene by fusion of the ler promoter with the luxCDABE operon of Photorhabdus luminescens (ler-lux C. rodentium) (12). Thus, ler-lux C. rodentium were introduced into tnrsf13b mutant and wild type mice and

105 days later ler expression was assayed in the intestinal walls. As Figure 2 A and B show, expression of ler was $\sim 8$-40-fold higher in organisms introduced into wild type than into mono-allelic or bi-allelic A144E mutant mice. Decreased expression of ler expression in tnrsf $13 \mathrm{~b}$ mutant mice was paralleled by decreased excretion of viable organisms. Thus, mono-allelic and bi-allelic A144E mutant mice excreted 11-fold and 114-fold fewer viable organisms respectively than wild type mice (Figure 2C). Thus, A144E heterozygosity and the dominant negative phenotype are associated with and possibly cause nearly full suppression of ler expression and a profound decrease in excretion of viable C. rodentium. To confirm that concept, we tested whether induction of ler before infection vitiate differences between mutant and wild type. Figure 2D shows that inducing virulence in C. rodentium prior to infection by culture in DMEM medium at $37^{\circ} \mathrm{C}(15)$ abrogates resistance of tnfrsfl 13 -mutant mice to that organism. These results demonstrate that resistance to C. rodentium infection is likely exerted prior to or during acquisition of virulence.

\section{Natural IgA induces $C$. rodentium virulence gene expression.}

Since thfrsfl3 governs B cell maturation and production of natural and elicited antibodies we wondered whether antibodies might exert a heretofore unrecognized impact on C. rodentium virulence. TNFRSF13B mutations in humans $(5,16,17)$ and tnrsfl3b mutations in mice $(3,18)$ are associated with decreased 
production of IgA and IgA maintains homeostasis of commensal bacteria in the gut, which in turn protects against certain gut pathogens (19). However, IgA is not required for the clearance of C. rodentium (20). Whether natural IgA could influence $C$. rodentium virulence has not been explored. To address that possibility, we first measured IgA in feces of un-manipulated thrsfl $3 B$ mutant and wild type mice. Mono and biallelic A144E mutant mice had 10-100-fold less IgA in feces than wild type (Figure 2E). We next asked whether the amount of IgA in feces might influence the development of virulence by C. rodentium. Seven days after infection with ler lux C. rodentium the amount of IgA per $g$ of feces correlated significantly with ler expression by organisms attached to the intestinal walls (Figures 2E, 2F and S3B) and with $C$. rodentium $\mathrm{CFU}$ (Figure S3A). These results were consistent with the possibility that IgA influences the acquisition of virulence by $C$. rodentium.

To determine that IgA rather than other property of tnfrsf $13 \mathrm{~b}$ mutant mice influences the acquisition of virulence by $C$. rodentium, we tested whether mice with wild type tnfrsfl $13 b$ but harboring a mutation that compromises secretion of IgA into the small intestine would resist $C$. rodentium like tnfrsf $13 b$-mutants. Mice lacking the polymeric Ig receptor (pIgR-KO), which transports polymeric IgA from basolateral to apical membrane of intestinal epithelium and hence have little or no IgA in the gut (21) were infected with ler lux C. rodentium and ler expression and C. rodentium $\mathrm{CFU}$ in stool were measured days later. As expected, the pIgR-KO mice had 10-10,000 fold less IgA in the feces than wild type mice at baseline. After infection with ler lux C. rodentium, pIgR-KO mice had on average 20 -fold less ler luminescence (Figures $2 \mathrm{~A}$ and $2 \mathrm{~B}$ ) and $\sim 100$-fold less $C$. rodentium $\mathrm{CFU}$ in the feces (Figures $2 \mathrm{C}$ and $\mathrm{S} 3 \mathrm{~A}$ ) than wild type mice. Thus, absence of IgA rather than other facets of the tnfrsf $13 b$-mutant phenotype is associated with resistance to $C$. rodentium and presence of $\operatorname{IgA}$ with susceptibility to $C$. rodentium infection.

Given the association of IgA in gut with susceptibility to C. rodentium infection, we wondered whether IgA might in some way promote virulence. To test whether IgA can promote virulence, we tested whether supernatant of feces containing or lacking IgA induce virulence in C. rodentium. Thus, serial dilutions of 
supernatant obtained from fresh feces from naive wild type, tnfrsf $13 b$-mutant or PIgR-KO mice were added $C$ rodentium that had been grown in LB medium under conditions that support non-virulence and ler expression was then assayed. As figures 3A-3C show, supernatant from feces of wild type mice induced higher ( $>2.5$-fold) ler expression than supernatant from feces of tnfrsf13b-mutant or from PIgR-KO mice.

Further, supernatant from wild type feces administered by gavage to tnfrsf $13 b$-mutant mice restored virulence (Figure 3D). Furthermore, ler expression directly correlated with concentration of IgA (Figure 3E), consistent with IgA inducing virulence. To test whether IgA (the predominant Ig in stool) or IgG can directly induce virulence, purified polyclonal IgA (Figures 3E-F) and IgG (Figure S4A) were added to cultures of ler lux C. rodentium and luminescence was assayed 1 hour later. As Figure 3 and Figure S4A show, both IgA and IgG induced ler expression by C. rodentium in a concentration dependent manner. However since $\operatorname{IgG}$ is not present in the gut early during infection it is unlikely that "natural" $\operatorname{IgG}$ contributes to the induction of virulence in a non-inflamed gut. The impact of $\operatorname{IgA} / \operatorname{IgG}$ on $C$. rodentium virulence did not depend on complement as heating the supernatants to $56^{\circ} \mathrm{C}$ for 30 minutes to inactivate complement (22) did not efface induction of ler expression (Figure S4). Finally, we asked whether virulence-inducing IgA necessarily reflected production by mutant mice or could have been acquired from maternal transfer. Assay of IgA in stool of various combinations of mutants or wild type progeny of mutant or wild type mothers revealed the concentration of $\operatorname{IgA}$ in the gut was determined by the genotype of the progeny and not by the mother s' genotype (Figure 3G). mice have distinct properties.

Our findings suggest that $C$. rodentium apparently evolved to co-opt some property of gut IgA to signal induction of the virulence program and various disruptive mutations of thfrsf $13 b$ in mice and TNFRSF $13 B$ in humans were sustained possibly to avert infection and transmission of this class of organisms. Since IgG, which is not present to any great extent in normal gut, and Ig from all wild type animals yet tested induces virulence in $C$. rodentium, we reasoned that the "active" region of Ig likely resides in F(ab)2 
domains. To test that concept, we compared the sequences of IgH and IgL genes from IgA+C rodentiumspecific B cells isolated from the Peyers patches of mice 14 days after infection or 5 days after re-infection. Following re-infection, of 10 clones isolated from wild type mice, two, B4 IgC03 and D3 IgC09, were found repeatedly ( 3 and 2 times, respectively). All of the clones were encoded by one of $3 \mathrm{VH}$ regions VH1, VH3 or VH5. Six of ten HC sequences were $>98 \%$ homologous to germline (Tables S1 and S2). The HC Ig sequences also had short CDR3 and short N-regions (non-templated nucleotide additions during $\mathrm{V}(\mathrm{D}) \mathrm{J}$ recombination), as would be expected of antibodies arising from fetal lineage precursor cells with restricted terminal deoxynucleotidyl transferase (TdT) activity (23). Only 59\% of the mutations observed were non-synonymous suggesting absent or weak antigen selection (Table S2). These properties are characteristic of natural antibodies (24). In contrast, the sequences of IgH from A144E homozygous mice were characteristic of elicited responses. Upon re-infection, only $40 \%$ of the clones from mutant mice contained germline sequences and none were repeated, indicating greater diversity than the wild type (Tables S3 and S4). C. rodentium-specific IgA clones from A144E homozygous mice had longer N regions than clones from wild type mice and although the overall mutation frequency in clones from A144E homozygous mice was low, on average (3.6\%), 70\% of the mutations were non-synonymous suggesting weak antigen selection. C. rodentium-specific IgA clones from A144E homozygous mice had longer heavy chain CDR3s (on average the $\mathrm{HC}$ CDR3s from A144E homozygous mice were 3 amino acids longer than the HC CDR3s from wild type mice) (Figures 4A-C). Tnfrsf13b-mutant mice did not have decreased frequency of C. rodentium + IgA B cells or of CD19+ B cells in the Peyers patches (Figure S5B) compared to WT mice; Tnfrsf13b-mutant mice had as many T cells and increased frequency of B cells in the spleen compared to WT mice (Figure S5C).

To determine what properties of IgA were attributable to the genotype as opposed to those determined by the environment, we sequenced $\operatorname{Ig} \mathrm{A}(\mathrm{H}+\mathrm{L})$ from single cells using 10X GEM technology obtained from A144E/WT or A144E/A144E littermates, 14 days after infection. The results shown in figures 4D-G and 
decreased frequencies of germline sequences. These results show that thfrsfl $3 b$ mutant mice have reduced natural $\operatorname{Ig} \mathrm{A}$ in the gut and instead produce adaptive $\operatorname{IgA}$.

\section{Tnfrsf13B A144E or PIgR-KO alleles control C. rodentium spreading.}

C. rodentium might exploit germline encoded natural $\operatorname{IgA}$ to secure a niche and prolong residence in the gut. However, this adaptation would be eclipsed if germline-encoded IgA hindered transmission of virulent organisms. To evaluate this possibility, we examined the transmissibility of $C$. rodentium from wild type and from various mutant strains of mice to uninfected susceptible wild type mice (Figures $4 \mathrm{G}$ and $4 \mathrm{H}$ ). Wild type or tnfrsf $13 B$-mutant mice were infected with C. rodentium (founder mice) and co-housed mice were tested for infection 7 days later. Wild type mice transmitted disease to 21 of 25 co-housed wild type mice (84\%). Mono-allelic A144E mice in contrast transmitted C. rodentium to no other co-housed mice whether wild type or mutant. Bi-allelic A144E transmitted C. rodentium to only 4 out of 13 (30.8\%) and PIgR-KO transmitted infection to 2 of 5 (40\%) co-housed wild type mice. Thus, natural IgA not only induces virulence, it also enables transmission of $C$. rodentium within a colony. Our results suggest the extraordinary frequency tnfrsf $13 b$ mutations might in part have been preserved to counter this vulnerability.

\section{Discussion}

Here we report what may be the truest example of balancing selection and co-evolution. Balancing selection ideally requires: (a) variant alleles where each variant is maintained at a particular equilibrium frequency; (b) a distinct benefit afforded by some fraction of the variants and/or heterozygous advantage; (c) a biological cost. In one famous example of balancing selection, the sickle cell $\beta$-globin gene is maintained in populations because the heterozygous state affords resistance to malaria at the cost of homozygote associated sickle cell disease (25). We show in this report that tnfrsfl $3 b$-mutant alleles that impair receptor function enhance resistance to C. rodentium and limit bacterial dissemination because of decreased natural IgA which C. rodentium has co-opted to express virulence. 
Like the sickle cell $\beta$-globin gene the advantage given by TNFRSF13B mutants comes with a biological cost. Indeed, TNFRSF13B mutants are associated with common variable immune-deficiency (CVID) (5) and auto-immunity (26). In contrast to the sickle cell $\beta$-globin gene TNFRSF13B polymorphisms govern many facets of immunity. We propose that TNFRSF13B polymorphisms, define a continuum of immune responses by controlling aspects of both innate and adaptive immunity. We $(1,2)$ and others $(27)$ showed that tnfrsfl $3 b$ governs differentiation of plasma cells, controls the synthesis of "natural IgA antibodies" [in this communication] and determines affinity maturation of antibodies by controlling functions of $\mathrm{B}$ and $\mathrm{T}$ helper follicular cells in the germinal center (4). While the sickle cell $\beta$-globin gene impacts only the carrier, tnfrsf $13 b$ polymorphisms might impact on the health of the community by limiting transmission of bacteria regulated by $L E E$-like loci. Our findings thus suggest that the high frequency of dominant-negative TNFRSF $13 B$ variants may be maintained by balancing selection.

Commensal organisms compete favorably against and hence suppress $C$. rodentium late in the course of infection (28). However, gut commensals are also required for C. rodentium colonization of the mucosa 15 (29). We found the composition of the microbiota to significantly differ between tnfrsf $13 \mathrm{~b}$ mutant and wild type mice (Figures S6 and S7) but that in itself did not explain the relative resistance to infection by tnfrsf $13 b$ mutant mice given the arguments that follow: (i) Normalization of the microbiota by co-housing (for 4 weeks) did not render tnfrsfl $13 b$ mutant mice susceptible or wild type mice resistant to C. rodentium infection; (ii) Transfer of feces SN from WT mice, that do not contain bacteria, to resistant Tnfrsfl3bmutant mice induces susceptibility; (iii) Progeny of WT or tnfrsfl3b-mutant mice manifest the susceptibility associated with their genotype (not the susceptibility associated with their mothers'). Thus, A144E heterozygous mice, obtained by crossing wild type mice with homozygous tnfrsf13b A144E mice, frequently resist infection or produce 20 -fold less CFUs than wild type littermates and thfrsf $13 b$ A144E/A144E and tnfrsf13b-KO mice, produced and backcrossed to C57BL/6 independently, are resistant. These facts support the resistant phenotype is a direct consequence of tnfrsf $13 b$ genotype. 
The prevailing concept is that $\operatorname{IgA}$ is protective $(19,30,31)$. $\operatorname{IgA}$ is thought to protect against pathogens by exerting direct effects such as neutralizing virulence (decreasing motility by binding to adhesins, pili, flagella) (32-34), by promoting entrapment in the mucus layer (35), immune exclusion (36), clearance by agglutination and enchained growth $(9,37)$ or by direct modulation of gene expression $(38,39)$. In one example, natural IgA protects against Salmonella thyphimurium and against necrotizing enterocolitis in newborn infants $(40,41)$. IgA may also protect against pathogens by indirect actions such as enhancing colonization by protective (anti-inflammatory) commensal species (42). For example, Bacteroides fragilis capsule induces specific IgA which in turn, increases its adherence to intestinal epithelial cells (31), and 10 commensals such as Bacteroides thetaiotaomicron utilize IgA to support mutualism(39). Our data instead indicate that $\operatorname{tnf} r \mathrm{~s} f 13 \mathrm{~b}$ mutants induce resistance to C. rodentium because of a relative depletion of $\operatorname{IgA}$ "natural" antibodies in the gut which induce C. rodentium virulence. Accordingly, WT feces SN (and polyclonal IgA alone) induce virulence, in accord to their IgA concentration. Furthermore, pIgR-deficient mice that have hardly any IgA in feces owing to an independent mechanism, are resistant to C. rodentium.

15 Other than our report, pathogens' adaptation to "natural" IgA to increase virulence and transmissibility has not to our knowledge been described. Because tnfrsf $13 b$ mutants maintain the ability to make "adaptive" $\operatorname{Ig} \mathrm{A}$ it is possible that protective functions of $\operatorname{Ig} \mathrm{A}$ are maintained.

For all the advantages IgA provides, IgA deficiency is the most common immune-deficiency with 20 frequencies varying between $1: 143$ in the Arabian peninsula to 1 in 500 Caucasian individuals $(43,44)$. This number may be underestimated since IgA-deficiency is often asymptomatic. One of us (Dr. Raif Geha) $(5,45)$ showed that all of the patients with TNFRSF13B mutations and common variable immunodeficiency examined also had IgA deficiency and that one $\operatorname{IgA-deficient}$ patient also had a TNFRSF $13 B$ mutation. In one recent study, Pulvirenti et al. (46) showed that 13\% IgA deficient patients carried at least one mutated TNFRSF13B allele. Most IgA-deficient individuals are asymptomatic and only 
a small percentage develop recurrent sino-pulmonary infections and/or auto-immune manifestations (43).

Given the limited morbidity of IgA deficiency, one might wonder whether benefits conferred by constraint on virulence of $L E E$-dependent enterobacteria outweigh the detrimental impact of decreased IgA in the gut. Data showing high frequency of $\mathrm{H}$ and $\mathrm{L}$ mutations in $C$. rodentium specific B cells in mutant mice suggest enhanced (compensatory) adaptive antibody responses. In accord, IgA-deficient patients were found to have enhanced adaptive antibody responses to pneumococcal vaccination (47). Perhaps it is this type of response that explains the mild phenotype of many individuals with IgA deficiency.

We show here that a common tnfrsfl3b variant even when expressed from a single allele together with the wild type gene induces resistance to an enterohemorrhagic microbe by blocking expression of virulence genes which in turn limit transmission and dissemination of disease. C. rodentium is a commonly used model for enteropathogenic infections in humans, dependent on the LEE locus. Given the pronounced impact of mono-allelic mutations, our findings identify a receptor that might be temporarily targeted to disrupt transmission of organisms in epidemics of organisms regulated by $L E E$-type loci.

\section{Materials and Methods}

\section{Experimental Models and Subject Details.}

Mice. C57BL/6 wild type (WT) mice were purchased from The Jackson Laboratory (C57BL/6J, The Jackson Laboratory, IMSR Cat\# JAX:000664; RRID: IMSR_JAX:000664). Polymeric Ig receptorknockout (pIgR-KO) (48), Tnfrsf13b- KO mice (6) and mice harboring bi-allelic (A144E/A144E) or monoallelic A144E variants (WT/A144E) (14), Tnfrsf13b, homologous to the human A181E, were previously described. All the knockouts and Tnfrsf13b-mutant mice were bred into the C57BL/6 background. In some experiments A144E/WT and WT littermates were obtained from crosses between WT mothers and A144E/WT males or from crosses between A144E/WT mothers and WT males. Animals of both genders 
between 8-20 weeks of age were maintained under specific pathogen-free conditions and all the experiments were performed in accordance with the approved animal protocol and the regulations of University of Michigan Committee on the Use and Care of Animals.

Citrobacter rodentium. The kanamycin (Km)-resistant wild type Citrobacter rodentium strain DBS120 (pCRP1:Tn5) was a gift of Dr. David Schauer, Massachusetts Institute of Technology, Massachusetts, USA (49); C. rodentium expressing GFP (50) used to identify C. rodentium-bound B cells, was a gift of Dr. Bruce Vallance, University of British Columbia, Vancouver, Canada; C. rodentium expressing a plasmid containing a ler/lux transcriptional fusion was previously described (12). Bacteria were grown overnight in Luria-Bertani (LB) broth supplemented with $\mathrm{Km}(50 \mu \mathrm{g} / \mathrm{ml})$ with agitation at $225 \mathrm{rpm}$, at $37^{\circ} \mathrm{C}$. To produce high and low virulence inoculum, $1 \mathrm{ml}$ of bacteria suspension was added into either $9 \mathrm{ml}$ of autoclaved LB with $\mathrm{Km}$ (low virulence) or to $9 \mathrm{ml}$ of DMEM (high virulence). Those cultures were incubated in agitation at $37^{\circ} \mathrm{C}$ for 6 more hours, bringing both culture concentrations to $10^{8} \mathrm{CFU} / \mathrm{ml}$.

\section{Methods Details}

Infections. Mice were infected by oral gavage with $0.2 \mathrm{ml}$ of PBS containing approximately $10^{8} \mathrm{CFU}$. At the designated time points, the feces were collected, weighed, suspended in $1 \mathrm{ml}$ of PBS and serially diluted. Optimally diluted feces were plated on MacConkey plates and cultured at $37^{\circ} \mathrm{C}$ overnight. The number of colonies was counted and the number of bacteria per $1 \mathrm{~g}$ of feces was calculated. Infection was considered cleared when no colonies were detected in the undiluted feces suspension. In some experiments, mice were given naïve C57BL/6 feces supernatants by gavage $(200 \mu \mathrm{l})$ twice, 24 hours before infection and 2 days after infection.

Measurement of ler expression. Ler expression was determined by measuring luminescence emitted by 25 ler/lux-expressing bacteria in PBS suspensions, or in gut tissue ex vivo. Luminescence was detected with bioluminescence imaging (BLI) using an IVIS200 (Xenogen Corporation, Alameda, CA). When measuring 
luminescence of bacteria attached to the intestinal wall, the entire gastrointestinal tract was removed, bisected, washed with PBS and placed into the light-tight chamber of the CCD camera system of the IVIS 200 immediately. For PBS suspensions of feces and mouse IgA and IgG (Southern Biotech, Cat\#0106-01; RRID: AB_2714214), $5 \times 10^{5}$ ler/lux-expressing C. rodentium were incubated for $1 \mathrm{~h}$ at room temperature with feces supernatant serial dilutions or different concentrations of mouse IgA.

Luminescence emitted from lux-expressing bacteria in the tissue was quantified using the Living Image Software v.4.7.2 (IVIS Imaging Systems, Xenogen Corporation, RRID:SCR_014247). Relative Luminescence Units were obtained by dividing the total light measured in photons/s per unit of area in 10 minutes and dividing that number by the background luminescence, followed by standardization for the weight of feces when supernatants were used. Quantitative real time RT-PCR (qPCR) for ler was performed using a SYBR green PCR master mix to confirm that luminescence reflected ler expression according to Kamada et al. (12). Briefly, the expressions of ler and Km resistant protein were detected by qPCR using respectively 5'-AAT ATA CCT GAT GGT GCT CTT G-3' and 5'-TTC TTC CAT TCA ATA ATG CTT CTT-3', and 5'-CTG AAT GAA CTG CAG GAC GA-3' and 5'-ATA CTT TCT CGG CAG GAG CA-3' and the expression of the virulence factor ler was normalized to the expression of Km resistant protein. The relative expression of ler was determined as fold change when compared to the expression of bacteria cultured in LB medium.

Detection of total C. rodentium-reactive Igs. To detect mouse Ig Nunc MaxiSorp ELISA plates were coated for $1 \mathrm{~h}$ at room temperature with goat anti-mouse $\mathrm{Ig}(\mathrm{H}+\mathrm{L})(4 \mu \mathrm{g} / \mathrm{ml}$; Southern Biotech, Cat\#101001; RRID: AB_2794121). Citrobacter rodentium-specific Ig was quantified by coating Nunc MaxiSorp ELISA plates with $10^{8}$ bacteria/well heat-inactivated at $60^{\circ} \mathrm{C}$ for $1 \mathrm{~h}$. After blocking, the plates were incubated with serial dilutions of mouse sera or feces supernatant for $1 \mathrm{~h}$ at room temperature. Bound $\operatorname{IgG}$, IgM or IgA were detected by adding HRP-conjugated goat anti-mouse IgG ( $4 \mu \mathrm{g} / \mathrm{ml}$; Southern Biotech, 
Cat\#1030-05; RRID: AB_2619742), goat anti-mouse IgM (4 $\mu \mathrm{g} / \mathrm{ml}$; Southern Biotech, Cat\#1020-05; RRID: AB_2794201) or goat anti-mouse IgA (4 $\mu \mathrm{g} / \mathrm{ml}$; Southern Biotech, Cat\#1040-05; RRID: AB_2714213). The reaction was visualized by subsequent addition of 2,2'-Azino-bis (3ethylbenzthiazoline-6-sulfonic acid) substrate (Southern Biotech, \#0202-01).

Flow Cytometry, Sorting and Antibodies. Peyer's patches' lymphocytes were isolated from naïve or infected mice as reported by Tsuji et al. and Cascalho et al. (1, 51). Cell viability was assed via BD Horizon Fixable Viability Stain 780 (FVS780; $1.11 \mu \mathrm{g} / \mathrm{ml}$; BD Biosciences, \#565388) and cells were stained with APC rat anti-mouse CD19 (1D3; $10 \mu \mathrm{g} / \mathrm{ml}$; BD Biosciences, Cat\#550992; RRID: AB_39848), PE rat anti mouse IgA (mA-6E1, $4 \mu \mathrm{g} / \mathrm{ml}$; Thermo Fisher Scientific, Cat\#12-4204-82; RRID: AB_465917) and $C$. rodentium expressing GFP. Staining were performed in $10^{6}$ cells, data were acquired with a BD FACS Canto II (BD Biosciences, Franklin Lakes, NJ) and 100,000 events were analyzed with FlowJo v.10.6.1 (FlowJo, RRID:SCR_008520). Single cell sorting was done on 96-well plates using a FACS Aria II (BD Biosciences, Franklin Lakes, NJ) in the Biomedical Research Facilities Core at the University of Michigan.

15 To quantify IgA binding to C. rodentium in non-infected mice, feces supernatants were diluted at $10 \mathrm{mg} / \mathrm{ml}$ in PBS and binding of feces IgA to C. rodentium was detected by flow cytometry. Briefly, $10^{8}$ C. rodentium expressing GFP were incubated with various dilutions of feces supernatant for 30 mins at $4^{\circ} \mathrm{C}$. Bacteria were then washed and bound IgA was detected with a PE-conjugated rat anti-mouse IgA (mA-6E1, $4 \mu \mathrm{g} / \mathrm{ml}$; Thermo Fisher Scientific, Cat\#12-4204-82; RRID: AB_465917). Data were acquired with a BD FACS Canto II (BD Biosciences, Franklin Lakes, NJ), 100,000 events were recorded in the C. rodentium-GFP gate, and were analyzed with FlowJo v.10.6.1 (FlowJo, RRID:SCR_008520). 
Ig gene sequencing. IgA-positive GFP-C. rodentium-positive B cells obtained from the Peyer's patches of mice re-infected with $C$. rodentium 5 days earlier were single cell-sorted into of U-bottom 96-well plates according to methods adapted from Tiller et al. (52). In brief, cells were sorted into PCR plates containing $4 \mu \mathrm{l} /$ well of ice-cold 0.5X PBS supplemented with $10 \mathrm{mM}$ DTT (Invitrogen, Cat\#Y00147), 8 U RNasin Ribonuclease Inhibitor (Promega, Cat\#N2115), and 3 U Recombinant RNase Inhibitor (Takara, Cat\#2313A ), sealed and immediately frozen on dry ice. Total RNA from single-sorted B cells was reverse transcribed in the original sorting plate with 150 ng Random Hexamer Primer (Thermo Scientific, Cat\#S0142), 1 mM dNTP Mix (Invitrogen, Cat\#18080044), 7 mM DTT (ThermoScientific, Cat\#P2325), 0.5\% v/v IGEPAL CA-630 (Sigma-Aldrich, Cat\#I3021-50ML), 4 U RNasin Ribonuclease Inhibitor (Promega, Cat\#N2115), 6 U Recombinant RNase Inhibitor (Takara, Cat\#2313A ) and 50 U Superscript III reverse transcriptase (Invitrogen, Cat\# 18080-044) and nuclease-free water in a final volume of $14 \mu 1 /$ well. Reverse transcription was performed at $42^{\circ} \mathrm{C}$ for $5 \mathrm{~min}, 25^{\circ} \mathrm{C}$ for $10 \mathrm{~min}, 50^{\circ} \mathrm{C}$ for $60 \mathrm{~min}$ and $94^{\circ} \mathrm{C}$ for $5 \mathrm{~min}$. cDNA was stored at $-20^{\circ} \mathrm{C}$. Mouse $\operatorname{Igh}, \operatorname{Ig} k$ and $\operatorname{Ig} l \mathrm{~V}$ gene transcripts were amplified by two rounds of semi-nested (Igh) or nested (Igk and $I g l$ ) PCR in 96-well plates containing $200 \mathrm{nM}$ each primer or total primer mix (Table S7), $300 \mu \mathrm{M}$ of dNTP Mix (Invitrogen, Cat\#18080044) and 1.2 U HotStart Taq DNA polymerase (Qiagen, Cat $\# 203205)$. The first round of reactions was performed with $3.5 \mu 1$ of cDNA at $94^{\circ} \mathrm{C}$ for 15 min followed by 50 cycles of $94^{\circ} \mathrm{C}$ for $30 \mathrm{~s}, 56^{\circ} \mathrm{C}(\operatorname{Igh})$ or $50^{\circ} \mathrm{C}(\operatorname{Ig} k)$ or $58^{\circ} \mathrm{C}(\operatorname{Igl})$ for $30 \mathrm{~s}, 72^{\circ} \mathrm{C}$ for $55 \mathrm{~s}$, and final incubation at $72^{\circ} \mathrm{C}$ for $10 \mathrm{~min}$. After identification of the Light chain genes the semi-nest or nested second round PCR was performed with $3.5 \mu \mathrm{l}$ of first round PCR product as template and combinations of $\mathrm{V}, \mathrm{J}$ and C primers (Table S7) at $94^{\circ} \mathrm{C}$ for $15 \mathrm{~min}$ followed by 50 cycles of $94^{\circ} \mathrm{C}$ for $30 \mathrm{~s}, 60^{\circ} \mathrm{C}(\operatorname{Igh})$ or $45^{\circ} \mathrm{C}(\operatorname{Igk})$ or $58^{\circ} \mathrm{C}(\operatorname{Igl})$ for $30 \mathrm{~s}, 72^{\circ} \mathrm{C}$ for $45 \mathrm{~s}$, and final incubation at $72^{\circ} \mathrm{C}$ for $10 \mathrm{~min}$. PCR products were treated with ExoSAP-IT PCR Product Cleanup Reagent (Applied Biosytems, Cat\#78201.1.ML) and sequencing was performed by the Sanger method at the University of Michigan Sequencing Core. Analysis of the sequences was done by using the IMGT portal (53-55) (RRID:SCR_011812), alignments were by Multiple sequence alignment by Log-expectation, MUSCLE software (56, 57) (RRID:SCR_011812). Comparisons of the amino acid composition of $C$. rodentium-specific IgA heavy chain (HC) was done using the Kullback- 
Leibler logotype using the Seq2Logo 2.0 software

(http://www.cbs.dtu.dk/biotools/Seq2Logo/index.php). Primer sequences are described on Table S8. Alternatively, IgA-positive GFP-C. rodentium-positive B cells obtained from the Peyer's patches of mice infected with $C$. rodentium 14 days earlier were sorted as explained above in PBS $0.004 \%$ BSA and up to 10,000 cells were analyzed by Chromium Next Gel Bead-in-Emulsions (GEM) Single Cell V(D)J Technology. Briefly, cells were identified via generation of GEMs by combining barcoded Single Cell V(D)J 5' Gel Beads v1.1, a master mix with cells (Chromium Next GEM Single Cell 5' Library and Gel Bead Kit v1.1; 10x Genomics Cat\#1000165), and partitioning Oil on Chromium Next GEM Chip G (Chromium Next GEM Chip G Single Cell Kit; 10x Genomics Cat\#1000127) and reverse transcription and cDNA amplification were performed as recommended by the manufacturer. Next, the targeted enrichment from cDNA was conducted with the Chromium Single Cell V(D)J Enrichment Kit, Mouse B Cell (10x Genomics Cat\#1000072). The cDNA quality control (QC) analysis was carried out in an Agilent 2100 Bioanalyzer (Agilent Technologies, Santa Clara, CA) using the Agilent High Sensitivity DNA Kit (Agilent Technologies Cat\#5067-4626). The V(D)J enriched library was then constructed via Chromium Single NovaSeq ${ }^{\text {TM }} 6000$ Sequencing System (Illumina, San Diego, CA). V(D)J sequences were collapsed using Cell Ranger: V(D)J Pipelines (10x Genomics, Pleasanton, CA, RRID:SCR_017344) and the V usage and clonotype profiles were generated and visualized by Loupe VDJ Browser. We were able to recover between 200 to $>8,000$ cell barcodes per sample.

16S RNA sequencing. DNA was extracted from feces pellets using the Qiagen MagAttract PowerMicrobiome DNA/RNA EP kit (QIAGEN, Cat\#27500-4-EP). The V4 region of the 16S rRNAencoding gene was amplified from extracted DNA using the barcoded dual-index primers developed by Kozich et al. (59) (Table S8). Samples were amplified using AccuPrime Taq DNA Polymerase, high fidelity (Invitrogen, Cat\# 12346086) at $95^{\circ} \mathrm{C}$ for 2 min followed by 30 cycles of $95^{\circ} \mathrm{C}$ for $20 \mathrm{~s}, 55^{\circ} \mathrm{C}$ for 15 
$\mathrm{s}$ and $72^{\circ} \mathrm{C}$ for $5 \mathrm{~min}$, and final incubation at $72{ }^{\circ} \mathrm{C}$ for $10 \mathrm{~min}$, purified using a magnetic bead capture kit (Agencourt AMPure; Beckman Coulter, Cat\#000130) and quantified using a fluorometric kit (Quant-iT PicoGreen dsDNA Assay Kit; Invitrogen, Cat\#P7589). Purified amplicons were pooled in equimolar concentrations with a SequalPrep Normalization Plate Kit (Applied Biosystems, Cat\#A1051001) and sequenced on Illumina MiSeq System (RRID:SCR_016379). Bioinformatic analysis was done using the Mothur v.1.42.3 software package (60) (RRID:SCR_011947) available at the University of Michigan Microbial Systems Laboratory.

\section{Quantification and Statistical Analysis.}

10 Statistics. All comparisons were done with GraphPad Prism v.8.0.0 software (GraphPad Software, RRID:SCR_002798). When an assumption of normal distributions could not be made values in more than two groups were compared using Kruskal-Wallis test followed by a Dunn's multiple comparison tests. Comparisons of two groups were done by Mann-Whitney test or Wilcoxon test for paired analysis. When an assumption of Gaussian distribution could be made averages were compared by unpaired test or when comparing more than 2 groups, using One-way ANOVA followed by multiple comparisons tests. Correlations were determined by the Spearman rank test. Differences in bacterial community structure were analyzed using analysis of molecular variance (AMOVA) in Mothur v.1.42.3 (60) (RRID:SCR_011947). Data are shown as mean \pm SEM. A $P$ value of equal or less than 0.05 was considered significant. Further information about which the statistical tests used in each experiment and experimental number can be found in the Figure Legends.

Data and Code Availability. The published study includes all datasets analyzed during this study.

\section{Author Contributions}


Conceptualization, M.C. and J.L.P.; Methodology, M.C. and J.L.P.; Experimental, M.G.M.B., D.H., A.R.L., J.K., C.K., C.M.B. and C.W.; Writing - Original Draft, M.C.; Writing - Review \& Editing, M.C., M.G.M.B., C.M.B., C.W., R.G., R.B., G.N., N.K. and J.L.P.; Funding Acquisition, M.C. and J.L.P.; Resources, M.C., C.M.B., and J.L.P; Supervision, M.C. and J.L.P

\section{Acknowledgments:}

We would like to acknowledge Mr. Tyler Cox who helped with the drawings on figure 4. Microbiome data was produced by the University of Michigan Microbial Systems Molecular Biology Laboratory.

\section{Funding}

This research was supported by the NIH, the Department of Defense, the Department of Surgery at the University of Michigan and by a grant from the Microbiome Explorers Initiative at the University of Michigan Medical School (to M.C.).

\section{References and Notes:}

1. Tsuji S, Cortesão C, Bram R, Platt JL, and Cascalho M. TACI deficiency impairs sustained Blimp-1 expression in B cells decreasing long-lived plasma cells in the bone marrow. Blood. 2011;118(22):5832-9.

2. Mantchev GT, Cortesao C, Rebrovich M, Cascalho M, and Bram RJ. TACI is required for efficient plasma cell differentiation in response to T-independent type 2 antigens. The Journal of Immunology. 2007;179:2282-8.

3. Lee JJ, Rauter I, Garibyan L, Ozcan E, Sannikova T, Dillon SR, et al. The murine equivalent of the A181E TACI mutation associated with common variable immunodeficiency severely impairs B-cell function. Blood. 2009;114(11):2254-62.

4. Tsuji S, Stein L, Kamada N, Nunez G, Bram R, Vallance BA, et al. TACI deficiency enhances antibody avidity and clearance of an intestinal pathogen. J Clin Invest. 2014;124(11):4857-66.

5. Castigli E, Wilson SA, Garibyan L, Rachid R, Bonilla F, Schneider L, et al. TACI is mutant in common variable immunodeficiency and IgA deficiency. Nat Genet. 2005;37(8):82934.

6. von Bulow GU, van Deursen JM, and Bram RJ. Regulation of the T-independent humoral response by TACI. Immunity. 2001;14(5):573-82.

7. Salzer U, Bacchelli C, Buckridge S, Pan-Hammarstrom Q, Jennings S, Lougaris V, et al. Relevance of biallelic versus monoallelic TNFRSF13B mutations in distinguishing 
disease-causing from risk-increasing TNFRSF13B variants in antibody deficiency syndromes. Blood. 2009;113(9):1967-76.

8. Martinez-Gallo M, Radigan L, Almejun MB, Martinez-Pomar N, Matamoros N, and Cunningham-Rundles C. TACI mutations and impaired B-cell function in subjects with CVID and healthy heterozygotes. J Allergy Clin Immunol. 2013;131(2):468-76.

9. Zerbino DR, Achuthan P, Akanni W, Amode MR, Barrell D, Bhai J, et al. Ensembl 2018. Nucleic Acids Res. 2018;46(D1):D754-D61.

10. Quintana-Murci L. Human Immunology through the Lens of Evolutionary Genetics. Cell. 2019;177(1):184-99.

11. Mundy R, MacDonald TT, Dougan G, Frankel G, and Wiles S. Citrobacter rodentium of mice and man. Cellular microbiology. 2005;7(12):1697-706.

12. Kamada N, Kim YG, Sham HP, Vallance BA, Puente JL, Martens EC, et al. Regulated virulence controls the ability of a pathogen to compete with the gut microbiota. Science. 2012;336(6086):1325-9.

13. Fadlallah J, Sterlin D, Fieschi C, Parizot C, Dorgham K, El Kafsi H, et al. Synergistic convergence of microbiota-specific systemic IgG and secretory IgA. J Allergy Clin Immunol. 2019;143(4):1575-85 e4.

14. Jabara HH, Lee JJ, Janssen E, Ullas S, Liadaki K, Garibyan L, et al. Heterozygosity for transmembrane activator and calcium modulator ligand interactor A144E causes haploinsufficiency and pneumococcal susceptibility in mice. J Allergy Clin Immunol. 2017;139(4):1293-301 e4.

15. Yang J, Tauschek M, Hart E, Hartland EL, and Robins-Browne RM. Virulence regulation in Citrobacter rodentium: the art of timing. Microbial biotechnology. 2010;3(3):259-68.

16. Cunningham-Rundles C. Common variable immune deficiency: Dissection of the variable.

17. Rachid R, Castigli E, Geha RS, and Bonilla FA. TACI mutation in common variable immunodeficiency and IgA deficiency. Curr Allergy Asthma Rep. 2006;6(5):357-62.

18. Lee JJ, Jabara HH, Garibyan L, Rauter I, Sannikova T, Dillon SR, et al. The C104R mutant impairs the function of transmembrane activator and calcium modulator and cyclophilin ligand interactor (TACI) through haploinsufficiency. $J$ Allergy Clin Immunol. 2010;126(6):1234-41 e2.

19. Macpherson AJ, Yilmaz B, Limenitakis JP, and Ganal-Vonarburg SC. IgA Function in Relation to the Intestinal Microbiota. Annu Rev Immunol. 2018;36:359-81.

20. Maaser C, Housley MP, Iimura M, Smith JR, Vallance BA, Finlay BB, et al. Clearance of Citrobacter rodentium requires B cells but not secretory immunoglobulin A (IgA) or IgM antibodies. Infect Immun. 2004;72(6):3315-24.

21. Johansen FE, Pekna M, Norderhaug IN, Haneberg B, Hietala MA, Krajci P, et al. Absence of epithelial immunoglobulin A transport, with increased mucosal leakiness, in polymeric immunoglobulin receptor/secretory component-deficient mice. $J$ Exp Med. 1999;190(7):915-22.

22. Gleeson M, Herd L, and Burns C. Effect of heat inactivation of HIV on specific serum proteins and tumour markers. Ann Clin Biochem. 1990;27 ( Pt 6):592-4.

23. Reynolds AE, Kuraoka M, and Kelsoe G. Natural IgM is produced by CD5- plasma cells that occupy a distinct survival niche in bone marrow. J Immunol. 2015;194(1):231-42.

45 24. Chen Y, Chaudhary N, Yang N, Granato A, Turner JA, Howard SL, et al. Microbial symbionts regulate the primary Ig repertoire. J Exp Med. 2018;215(5):1397-415. 
25. Allison AC. Protection afforded by sickle-cell trait against subtertian malareal infection. Br Med J. 1954;1(4857):290-4.

26. Romberg N, Chamberlain N, Saadoun D, Gentile M, Kinnunen T, Ng YS, et al. CVIDassociated TACI mutations affect autoreactive B cell selection and activation. J Clin Invest. 2013;123(10):4283-93.

27. Ozcan E, Garibyan L, Lee JJ, Bram RJ, Lam KP, and Geha RS. Transmembrane activator, calcium modulator, and cyclophilin ligand interactor drives plasma cell differentiation in LPS-activated B cells. J Allergy Clin Immunol. 2009;123(6):1277-86 e5.

28. Kitamoto S, Nagao-Kitamoto H, Kuffa P, and Kamada N. Regulation of virulence: the rise and fall of gastrointestinal pathogens. J Gastroenterol. 2016;51(3):195-205.

29. Mullineaux-Sanders C, Collins JW, Ruano-Gallego D, Levy M, Pevsner-Fischer M, Glegola-Madejska IT, et al. Citrobacter rodentium Relies on Commensals for Colonization of the Colonic Mucosa. Cell Rep. 2017;21(12):3381-9.

30. Catanzaro JR, Strauss JD, Bielecka A, Porto AF, Lobo FM, Urban A, et al. IgA-deficient humans exhibit gut microbiota dysbiosis despite secretion of compensatory IgM. Sci Rep. 2019;9(1):13574.

31. Donaldson GP, Ladinsky MS, Yu KB, Sanders JG, Yoo BB, Chou WC, et al. Gut microbiota utilize immunoglobulin A for mucosal colonization. Science. 2018;360(6390):795-800.

32. Williams RC, and Gibbons RJ. Inhibition of bacterial adherence by secretory immunoglobulin A: a mechanism of antigen disposal. Science. 1972;177(4050):697-9.

33. Bunker JJ, and Bendelac A. IgA Responses to Microbiota. Immunity. 2018;49(2):211-24.

34. Cullender TC, Chassaing B, Janzon A, Kumar K, Muller CE, Werner JJ, et al. Innate and adaptive immunity interact to quench microbiome flagellar motility in the gut. Cell Host Microbe. 2013;14(5):571-81.

35. Boullier S, Tanguy M, Kadaoui KA, Caubet C, Sansonetti P, Corthesy B, et al. Secretory IgA-mediated neutralization of Shigella flexneri prevents intestinal tissue destruction by down-regulating inflammatory circuits. J Immunol. 2009;183(9):5879-85.

36. Stokes CR, Soothill JF, and Turner MW. Immune exclusion is a function of IgA. Nature. 1975;255(5511):745-6.

37. Hendrickx AP, Top J, Bayjanov JR, Kemperman H, Rogers MR, Paganelli FL, et al. Antibiotic-Driven Dysbiosis Mediates Intraluminal Agglutination and Alternative Segregation of Enterococcus faecium from the Intestinal Epithelium. mBio. 2015;6(6):e01346-15.

38. Bielinska AU, Janczak KW, Landers JJ, Makidon P, Sower LE, Peterson JW, et al. Mucosal immunization with a novel nanoemulsion-based recombinant anthrax protective antigen vaccine protects against Bacillus anthracis spore challenge. Infect Immun. 2007;75(8):4020-9.

39. Peterson DA, Planer JD, Guruge JL, Xue L, Downey-Virgin W, Goodman AL, et al. Characterizing the interactions between a naturally primed immunoglobulin A and its conserved Bacteroides thetaiotaomicron species-specific epitope in gnotobiotic mice. $J$ Biol Chem. 2015;290(20):12630-49.

40. Wijburg OL, Uren TK, Simpfendorfer K, Johansen FE, Brandtzaeg P, and Strugnell RA. Innate secretory antibodies protect against natural Salmonella typhimurium infection. $J$ Exp Med. 2006;203(1):21-6. 
41. Gopalakrishna KP, Macadangdang BR, Rogers MB, Tometich JT, Firek BA, Baker R, et al. Maternal IgA protects against the development of necrotizing enterocolitis in preterm infants. Nat Med. 2019;25(7):1110-5.

42. Fadlallah J, El Kafsi H, Sterlin D, Juste C, Parizot C, Dorgham K, et al. Microbial ecology perturbation in human IgA deficiency. Sci Transl Med. 2018;10(439).

43. Yel L. Selective IgA deficiency. J Clin Immunol. 2010;30(1):10-6.

44. Wang N, and Hammarstrom L. IgA deficiency: what is new? Current opinion in allergy and clinical immunology. 2012;12(6):602-8.

45. Castigli E, and Geha RS. TACI, isotype switching, CVID and IgAD. Immunol Res. 2007;38(1-3):102-11.

46. Pulvirenti F, Zuntini R, Milito C, Specchia F, Spadaro G, Danieli MG, et al. Clinical Associations of Biallelic and Monoallelic TNFRSF13B Variants in Italian Primary Antibody Deficiency Syndromes. J Immunol Res. 2016;2016:8390356.

47. Edwards E, Razvi S, and Cunningham-Rundles C. IgA deficiency: clinical correlates and responses to pneumococcal vaccine. Clin Immunol. 2004;111(1):93-7.

48. Shimada S, Kawaguchi-Miyashita M, Kushiro A, Sato T, Nanno M, Sako T, et al. Generation of polymeric immunoglobulin receptor-deficient mouse with marked reduction of secretory IgA. Journal of immunology. 1999;163(10):5367-73.

49. Schauer DB, and Falkow S. Attaching and effacing locus of a Citrobacter freundii biotype that causes transmissible murine colonic hyperplasia. Infection and immunity. 1993;61(6):2486-92.

50. Bergstrom KS, Kissoon-Singh V, Gibson DL, Ma C, Montero M, Sham HP, et al. Muc2 protects against lethal infectious colitis by disassociating pathogenic and commensal bacteria from the colonic mucosa. PLoS pathogens. 2010;6(5):e1000902.

51. Cascalho M, Wong J, and Wabl M. VH gene replacement in hyperselected B cells of the quasimonoclonal mouse. Journal of immunology. 1997;159(12):5795-801.

52. Tiller T, Busse CE, and Wardemann H. Cloning and expression of murine Ig genes from single B cells. Journal of immunological methods. 2009;350(1-2):183-93.

53. Alamyar E, Giudicelli V, Li S, Duroux P, and Lefranc MP. IMGT/HighV-QUEST: the IMGT(R) web portal for immunoglobulin (IG) or antibody and T cell receptor (TR) analysis from NGS high throughput and deep sequencing. Immunome research. 2012;8(1):26.

54. Rogosch T, Kerzel S, Hoi KH, Zhang Z, Maier RF, Ippolito GC, et al. Immunoglobulin analysis tool: a novel tool for the analysis of human and mouse heavy and light chain transcripts. Front Immunol. 2012;3:176.

55. Giudicelli V, Chaume D, and Lefranc MP. IMGT/GENE-DB: a comprehensive database for human and mouse immunoglobulin and $\mathrm{T}$ cell receptor genes. Nucleic Acids Res. 2005;33(Database issue):D256-61.

56. Edgar RC. MUSCLE: a multiple sequence alignment method with reduced time and space complexity. BMC bioinformatics. 2004;5:113.

57. Edgar RC. MUSCLE: multiple sequence alignment with high accuracy and high throughput. Nucleic acids research. 2004;32(5):1792-7.

58. Thomsen MC, and Nielsen M. Seq2Logo: a method for construction and visualization of amino acid binding motifs and sequence profiles including sequence weighting, pseudo counts and two-sided representation of amino acid enrichment and depletion. Nucleic acids research. 2012;40(Web Server issue):W281-7. 
59. Kozich JJ, Westcott SL, Baxter NT, Highlander SK, and Schloss PD. Development of a dual-index sequencing strategy and curation pipeline for analyzing amplicon sequence data on the MiSeq Illumina sequencing platform. Applied and environmental microbiology. 2013;79(17):5112-20.

60. Excoffier L, Smouse PE, and Quattro JM. Analysis of molecular variance inferred from metric distances among DNA haplotypes: application to human mitochondrial DNA restriction data. Genetics. 1992;131(2):479-91. 


\section{Figures:}

A

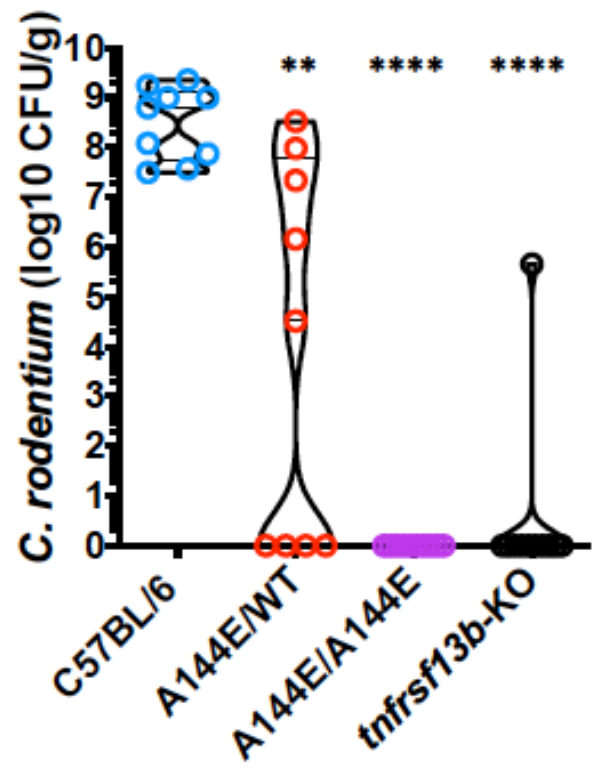

B

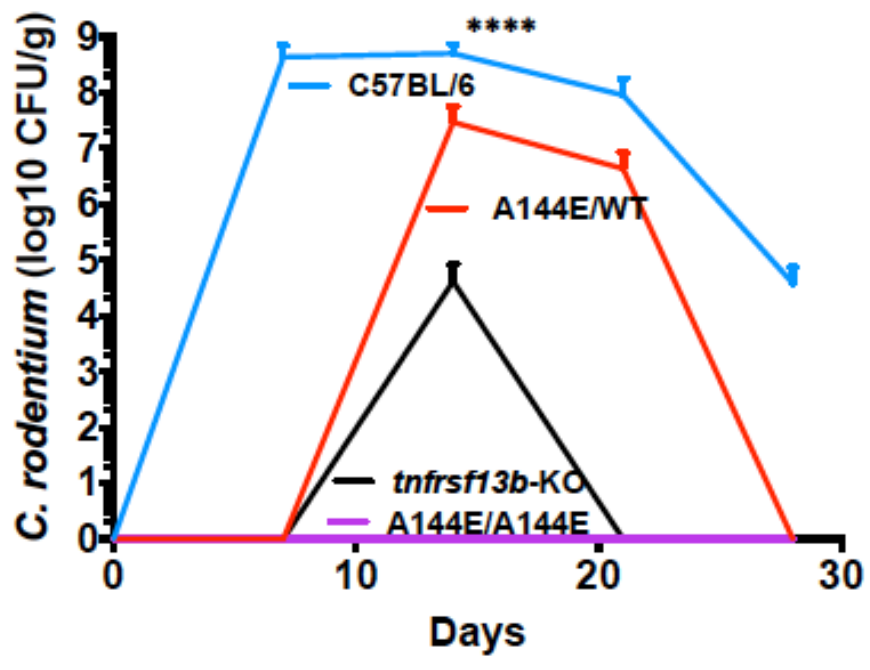

C

$\lg A$ in the gut prior to infection

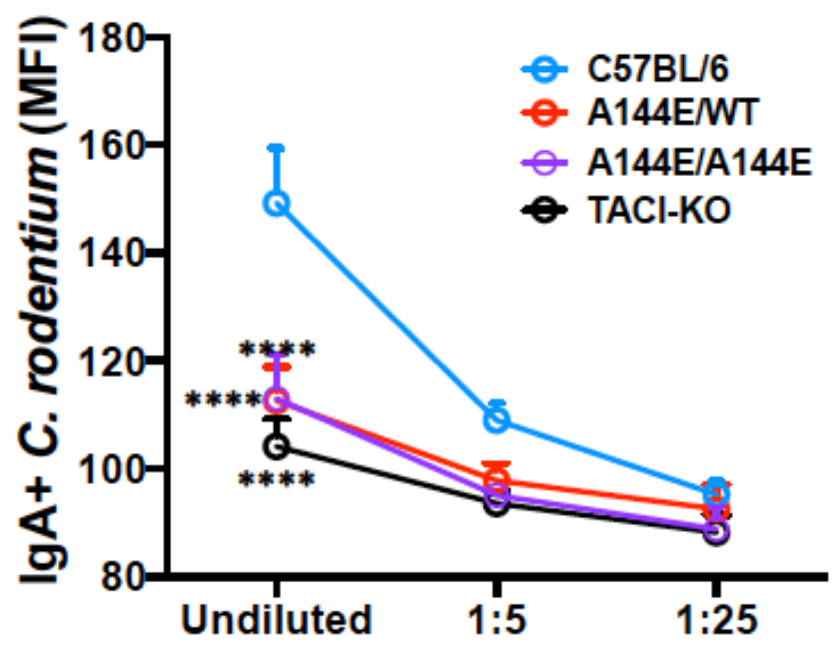

\section{Figure 1}


A

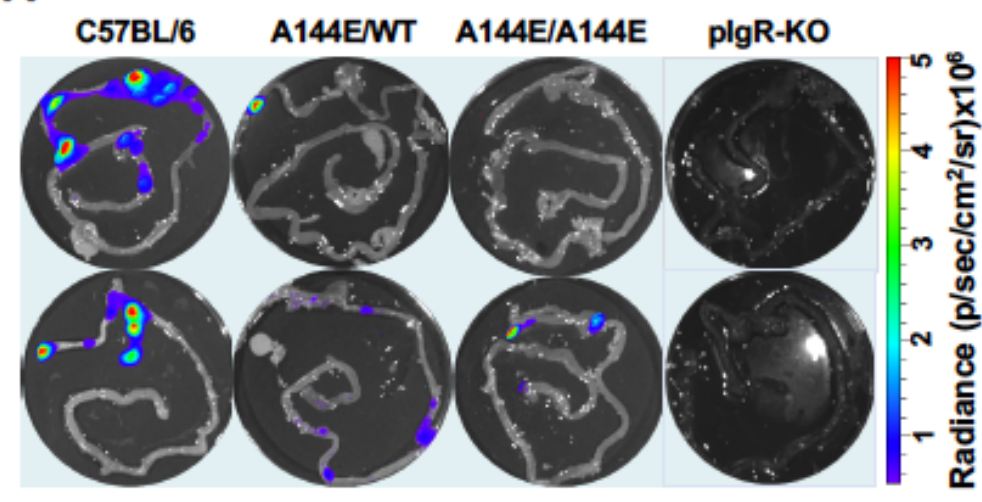

B

C

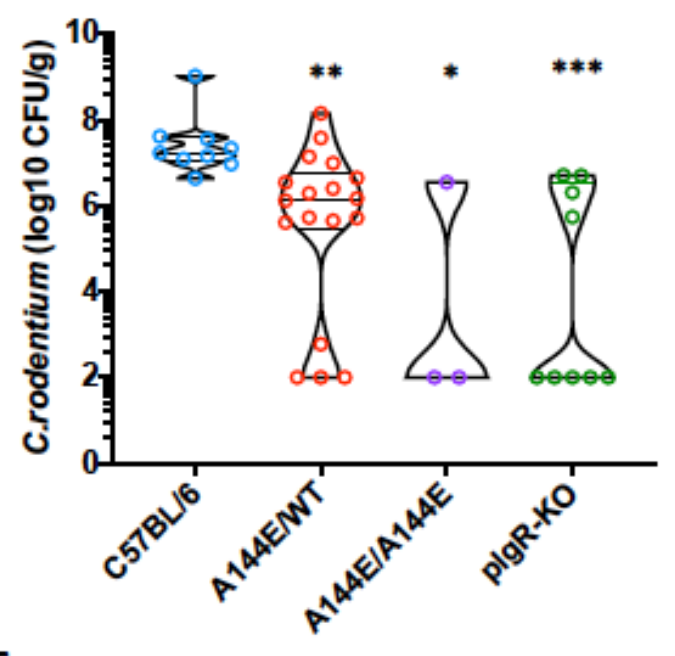

E

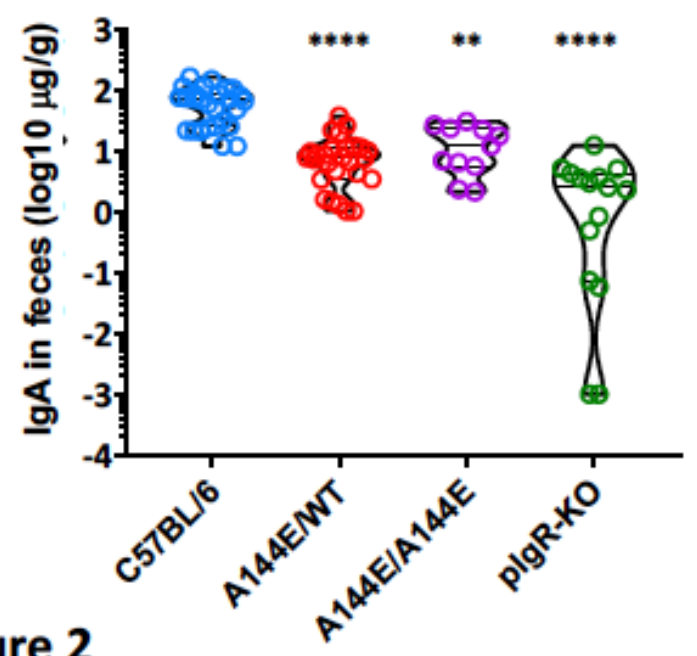

D

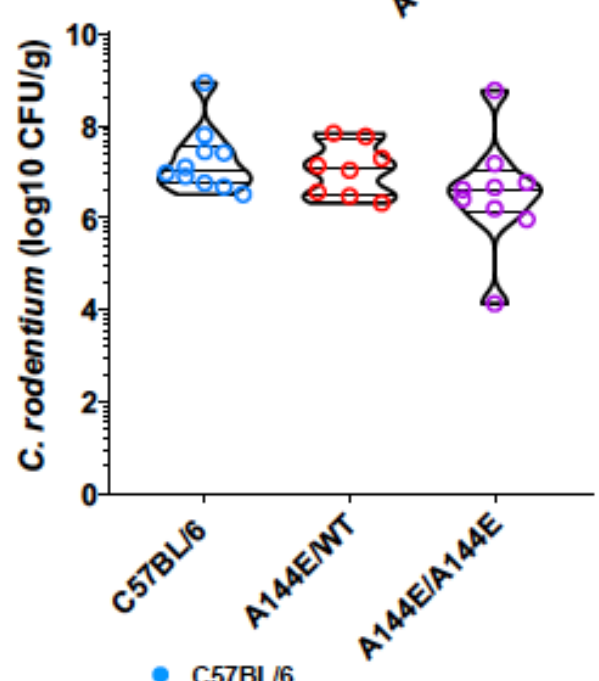

F

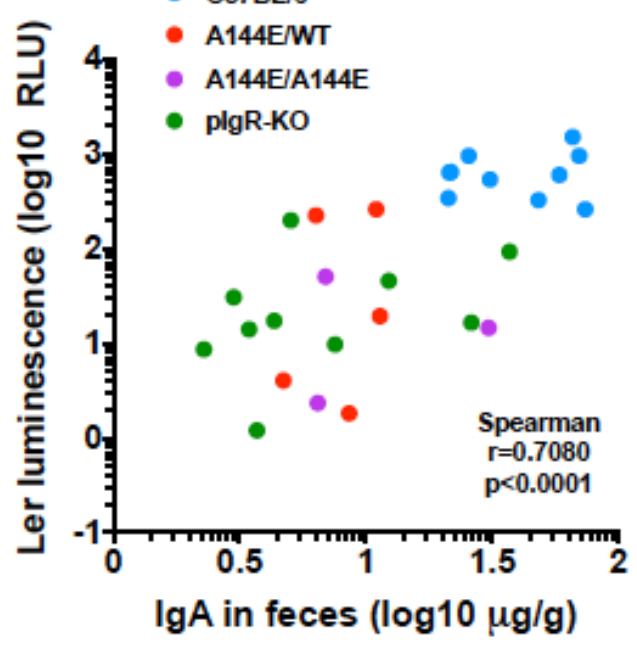

Figure 2

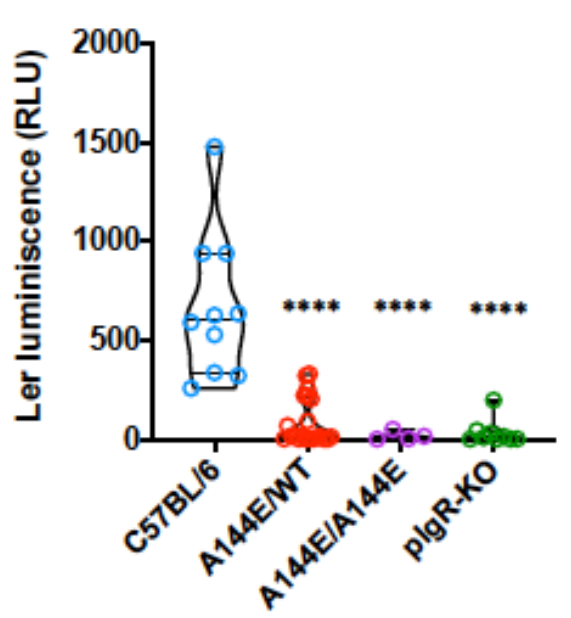




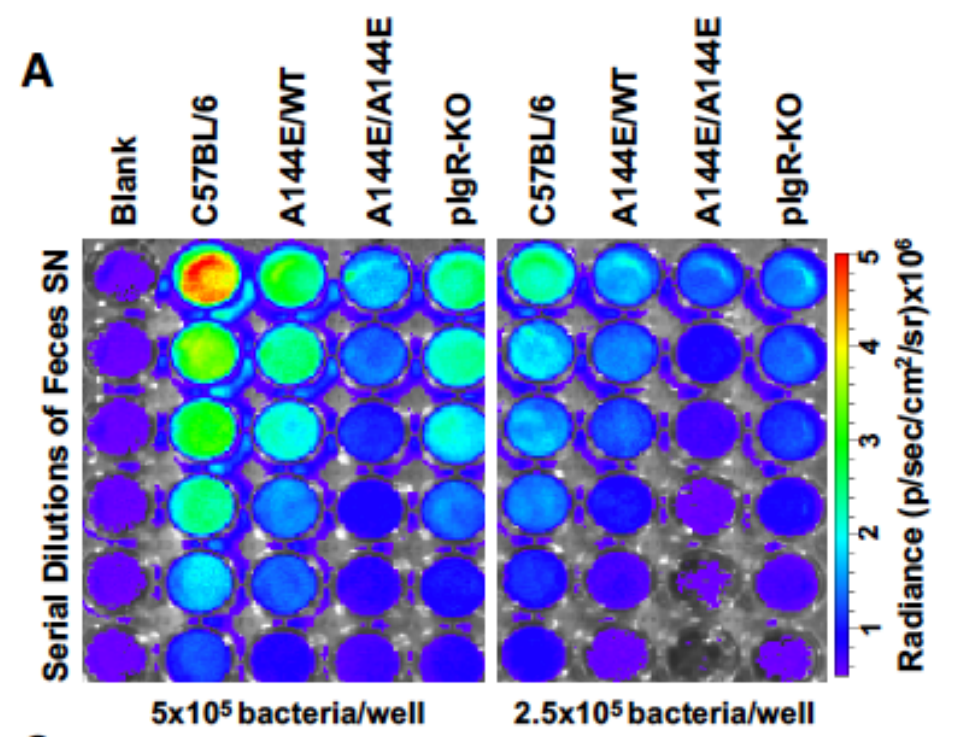

C

$5 \times 10^{5}$ bacteria/well

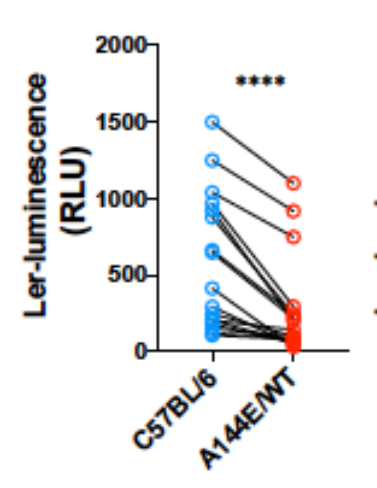

$\mathbf{E}$

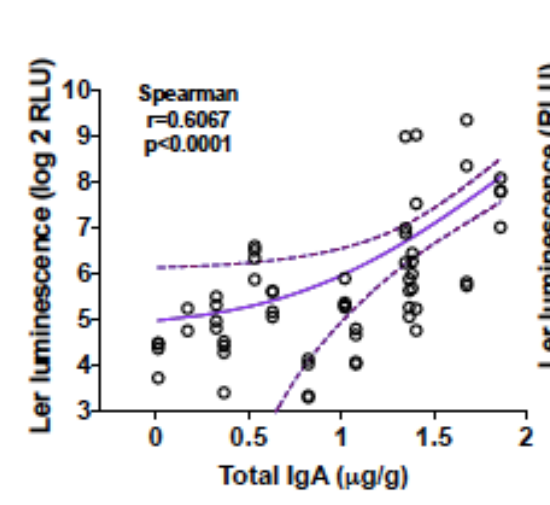

B

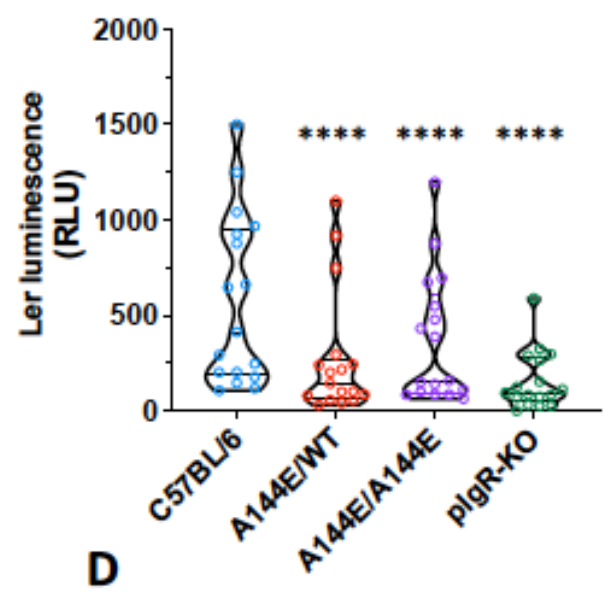

D

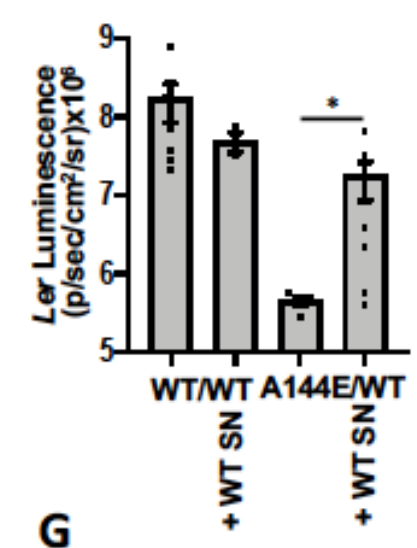

$\mathbf{F}$

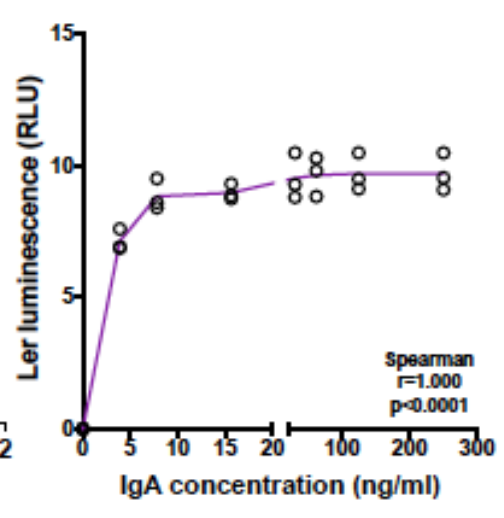

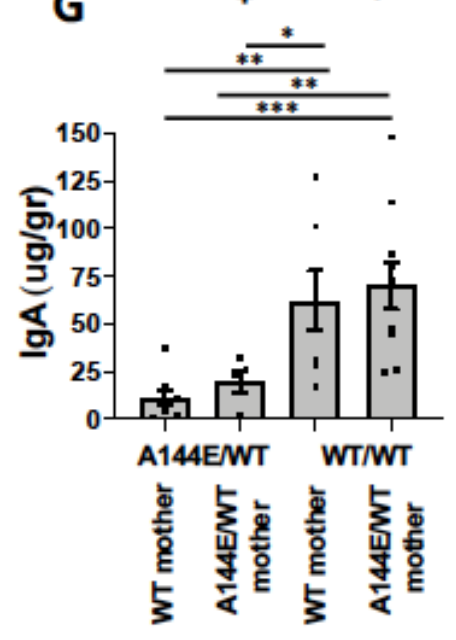

Figure 3 


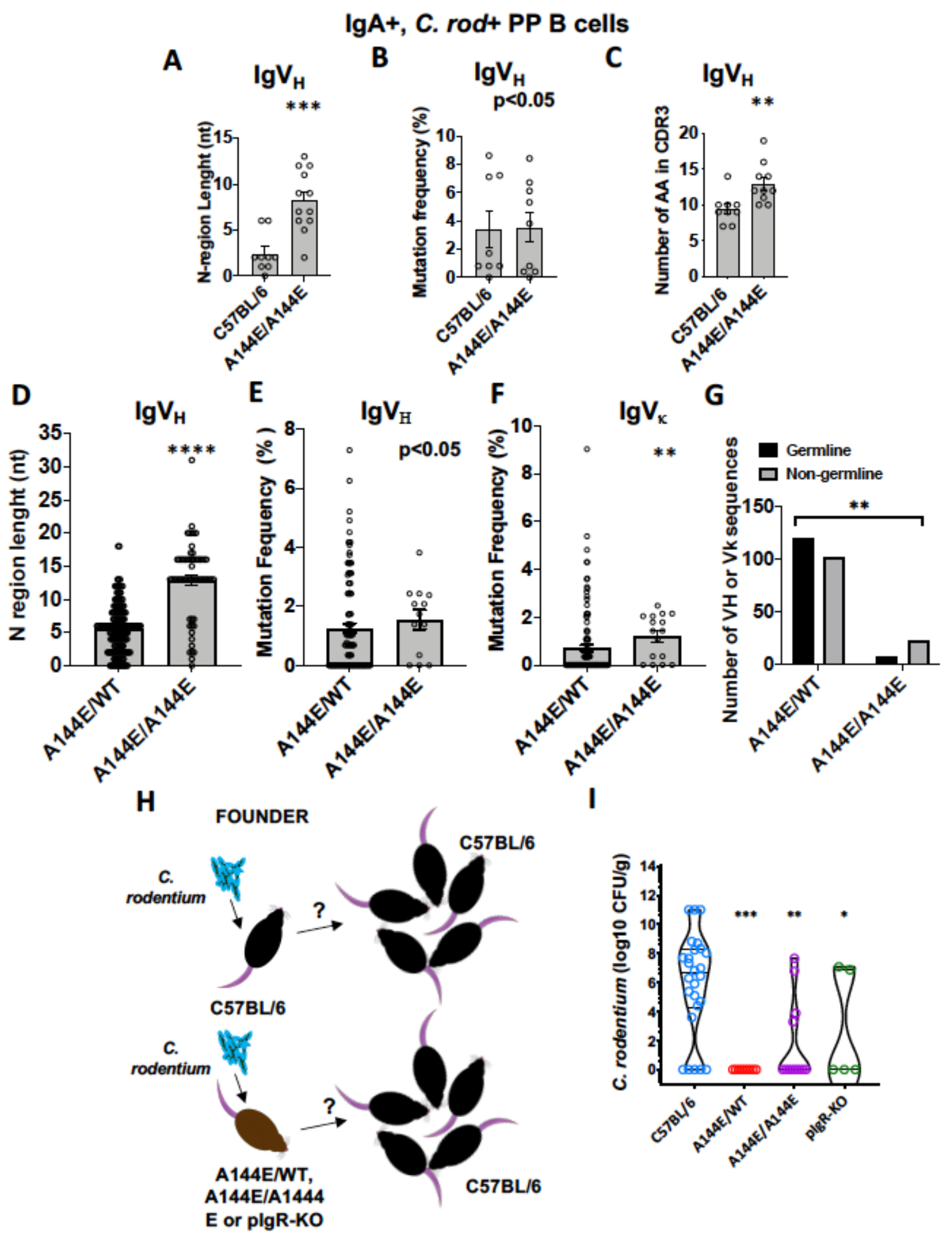

Figure 4 


\section{Figure Legends:}

Fig. 1. Tnfrsf13b-mutant mice resist infection with $\boldsymbol{C}$, rodentium. To evaluate baseline resistance to enteric infection with C. rodentium, wild type (WT) C57BL/6 mice and mice with monoallelic or biallelic mutations in tnfrsfl3b (A144E) and mice with targeted disruption of tnfrsf13b (tnfrsf13b-KO) were infected with $10^{8}$ C. rodentium by oral gavage and the numbers of viable organisms in stool were measured by counting CFU/g of feces after 18 hours of incubation on MacConkey plates at the peak of infection. (A) Graph depicts the maximum CFU/g of feces in the course of infection for each of the infected mouse strains. Values obtained in tnfrsfl $3 b$-mutant mice were compared to those in wild type by the Mann-Whitney test showing $\mathrm{p}=0.0017$ for $\mathrm{A} 144 \mathrm{E} / \mathrm{WT}, \mathrm{p}<0.0001$ for A144E/A144E and for tnfrsf $13 b$-KO mice. (B) Mean number of viable $C$. rodentium in stool (expressed in $\log 10 \mathrm{CFU} / \mathrm{g}$ of feces) at various times after infection. (C) Quantification of C. rodentium-binding IgA in feces of mice prior to infection. IgA in the feces was measured by flow cytometry analysis of IgA $+\mathrm{GFP}+C$. rodentium and detected with anti-IgA PE-labelled. Y-axis, Average of 3 independent measurements of IgA mean fluorescence intensity (MFI); X-axis, feces supernatant dilutions.

Fig. 2. Tnfrsf $13 b$-mutations block $\boldsymbol{C}$. rodentium virulence gene induction. (A and B) Ler expression measured by bioluminescence of ler/lux-C. rodentium attached to the intestinal wall of mice infected for 7 days. (Graph depicts ler expression in relative light units, RLU, in each strain (Y-axis). RLU reflects the photons/s measured in each image divided by the background luminescence. Comparisons done with Oneway ANOVA yielded $\mathrm{p}<0.0001$, followed by multiple comparisons to C57BL/6 mice (control), yielded for A144E/WT, $\mathrm{p}<0.0001 ; \mathrm{A} 144 \mathrm{E} / \mathrm{A} 144 \mathrm{E}, \mathrm{p}<0.0001$; and for $\mathrm{pIgR}-\mathrm{KO}, \mathrm{p}<0.0001$. (C) Graph depicts the $C$. rodentium $\mathrm{CFU} / \mathrm{g}$ of feces obtained 7 days after infection for each of the infected mouse strains. Values obtained in tnfrsf $13 b$-mutant mice were compared to those in wild type by the One-way ANOVA $(\mathrm{p}<0.0001)$ followed by the Kruskal-Wallis test showing $\mathrm{p}=0.0090$ for A144E/WT, $\mathrm{p}=0.0153$ for $\mathrm{A} 144 \mathrm{E} / \mathrm{A} 144 \mathrm{E}$ and $\mathrm{p}=0.0008$ for $p \operatorname{Ig} R-\mathrm{KO}$ mice. (D) Graph shows $\mathrm{CFU} / \mathrm{g}$ of feces in $\mathrm{C} 57 \mathrm{BL} / 6$ or 
tnfrsf13b-mutant mice 14 days following infection with $10^{8}$ C. rodentium grown overnight in DMEM medium and expressing ler. Statistical analysis was by the Kruskal-Wallis test. High virulence $C$. rodentium infects wild type and tnfrsf13b-mutant mice equally ( $\mathrm{p}>0.05$ ). (E) IgA concentration measured in feces 7 days after infection, by ELISA. Comparisons done with One-way ANOVA yielded $p<0.0001$, followed by multiple comparisons to C57BL/6 mice results (control) by the Kruskal-Wallis test, yielding for A144E/WT, $\mathrm{p}<0.0001$; A144E/A144E, $\mathrm{p}=0.0049$; and for $\mathrm{pIgR}-\mathrm{KO}, \mathrm{p}<0.0001$. (F) Correlation analysis between luminescence reflecting ler expression by bacteria attached to the gut walls and IgA concentration in feces supernatants obtained 7 days after infection. Spearman test $r=0.7080, p<0.0001$ indicating that $\operatorname{IgA}$ concentration in feces is correlated with ler expression.

Fig. 3. Ler expression increases directly with IgA concentration. Ler expression measured by bioluminescence imaging (BLI) of ler/lux C. rodentium incubated with serial dilutions of feces supernatants obtained from non-infected naïve C57BL/6, A144E/WT, A144E/A144E or pIgR-KO mice for one hour at $37^{\circ} \mathrm{C}$. (A) Example of a plate reading in a typical experiment. (B) Graph shows ler expression detected with BLI and expressed in Relative Luminescence Units (Y-axis), normalized for the feces weight in 12 independent experiments for each mouse strain (X-axis). Luminescence data in each mutant mouse was compared to the luminescence in the C57BL/6 group by One-way ANOVA $(p<0.0001)$ followed by the Holm-Sidak's multiple comparisons test $(\mathrm{p}<0.0001, * * * *)$. (C) Paired analysis of normalized (to the feces weight) individual measurements of ler expression (Y-axis), comparing luminescence obtained with supernatant (SN) from mutant mice with that from C57BL/6 mice, within each experiment (X-axis). Paired $\mathrm{t}$ test analysis yielded $\mathrm{p}<0.0001, * * * *$. (D) Ler expression measured by bioluminescence of ler/lux-C. rodentium attached to the intestinal wall of WT or A144E/WT mice infected for 7 days and treated (or not)

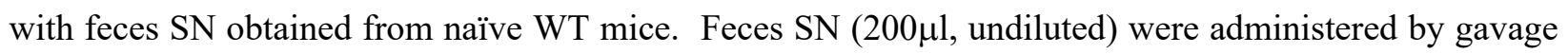
twice, one day prior and 2 days after infection. Gavage of WT SN increased C. rodentium virulence 25 following infection of A144E/WT mice. Comparisons done with Mann-Whitney tests yielded $\mathrm{p}=0.0212$. (E) Regression and correlation analysis between $\operatorname{IgA}$ concentration in the feces SN (X-axis) and ler 
expression (Y-axis). Continuous line represents the average and dotted lines the $95 \%$ confidence limit. The slope of the curve was different from 0 with $\mathrm{p}<0.0001$. Analysis by the Spearman test yielded $\mathrm{r}=0.6067$ and an approximate $\mathrm{p}<0.0001$ (two-tailed). (F) Ler-lux C. rodentium was incubated with serial dilutions of isolated polyclonal murine IgA in PBS for one hour at $37^{\circ} \mathrm{C}$. Y-axis, ler expression detected with bioluminescence imaging (BLI), X-axis, IgA concentration in $\mathrm{ng} / \mathrm{ml}$. (G) $\operatorname{IgA}$ concentration in feces of A144E/WT of WT mice born from WT or A144E/WT mothers. Mann-Whitney tests yielded $\mathrm{p}<0.001$, $* * * ; \mathrm{p}<0.01, * *, \mathrm{p}<0.05, *$.

Fig. 4: IgA sequences from sorted $C$. rodentium-bound IgA+ B cells of C57BL/6 and thfrsf13b-mutant mice have distinct properties and determine $C$, rodentium spreading. Single IgA-positive GFP- $C$. rodentium-bound B cells were sorted from the Peyers patches of infected C57BL/6, A144E/WT or A144E/A144E mice either 5 days following re-infection (A, B and C) or 14 days following primary infection (D, E, F and G) (See also Figure S5 and Tables S1-S7). IgA H+L sequences were obtained from cDNA by PCR followed by Sanger sequencing (A, B and C) or by next generation sequencing of barcoded single cell barcoded cDNA libraries (D, E and F). (A and D) Graphs compare the lengths of the N-regions (number of nucleotides) of CDR3 regions (in amino acids) of HC IgA sequences obtained from C57BL/6 A144E/WT or A144E/A144E mice. (B, E and F) Graphs depict the frequencies (\%) of mutated nucleotides in $\mathrm{V}_{\mathrm{H}}$ or $\mathrm{V \kappa}$ exons relative to their closest germline in $\mathrm{HC}$ sequences obtained from C57BL/6, A144E/WT or A144E/A144E mice. (C) Number of aminoacids (AA) in the complementary determining regions of Ig VH sequences obtained from C57BL/6 and A144E/A144E mice. Mann-Whitney test analysis yielded $\mathrm{p}=0.0066(\mathrm{~A}), \mathrm{p}=0.9196(\mathrm{~B}), \mathrm{p}=0.002(\mathrm{C}), \mathrm{p}<0.0001(\mathrm{D}), \mathrm{p}=0.1145(\mathrm{E})$ and $\mathrm{p}=0.0036(\mathrm{~F})$. (G) Contingency analysis of frequency of germline $C$. rodentium binding IgA, VH and Vk sequences obtained from A144E/WT or A144E/A144E mice. Chi-square test yielded a $\mathrm{p}=0.016$ indicating that germline sequences are rarer in A144E/A144E mice compared to A144E/WT mice. (H) Schematic of experimental protocol. Founder mice are either C57BL/6, tnfrsf $13 b$-mutant mice or pIgR-KO mice. Two founder mice were cohoused with 3 C57BL/6 mice/cage. Only founders were inoculated with low virulence $10^{8}$ C. rodentium. 
CFUs were counted on non-primarily infected mice 7 days after infection. (I) Graph depicts CFU/g of feces in mice not primarily infected according to the strain of the inoculated founders (depicted in the X-axis). Comparisons were by Kruskal-Wallis tests followed by Dunn's multiple comparison tests. Kruskal-Wallis yielded $\mathrm{p}<0.0001$; Dunn's multiple comparison tests yielded $\mathrm{p}=0.0111, * ; \mathrm{p}=0.0060,{ }^{* *}, \mathrm{p}=0.0004^{* * *}$.

\section{Supplementary Materials:}

\section{Supplementary Text}

\section{Figures S1 to S7}

